\title{
Pathogenesis of Rickets and Osteomalacia in Familial Hypophosphataemia
}

\author{
J. R. CONDON, J. R. NASSIM, and A. RUTTER \\ From St. George's Hospital, and Royal National Orthopaedic Hospital, London
}

\begin{abstract}
Condon, J. R., Nassim, J. R., and Rutter, A. (1971). Archives of Disease in Childhood, 46, 269. The pathogenesis of rickets and osteomalacia in familial hypophosphataemia. Calcium and/or phosphate tolerance tests were performed on patients with familial hypophosphataemia, normal control subjects, and patients with vitamin $\mathrm{D}$ deficient osteomalacia.

Intestinal calcium absorption was similar in patients with familial hypophosphataemia and control subjects. The phosphate tolerance test, which is known to be 'flat' in patients with familial hypophosphataemia, was normal in patients with vitamin $\mathrm{D}$ deficient osteomalacia.

These findings suggest that rickets and osteomalacia in familial and some cases of non-familial hypophosphataemia are unrelated to abnormal metabolism of vitamin $\mathrm{D}$. This hypothesis is supported by the fact that intestinal calcium absorption as measured by calcium tolerance test is normal in familial hypophosphataemia.

It is suggested that the primary abnormality in familial hypophosphataemia is a partial metabolic block in the intestinal absorption and renal tubular reabsorption of phosphate.
\end{abstract}

It is generally accepted that a low plasma phosphate plays an essential role in the aetiology of rickets and osteomalacia in familial and nonfamilial hypophosphataemia. The importance of the low plasma phosphate in these disorders is stressed by the fact that cartilage from affected patients only requires normal concentrations of calcium and phosphorus to calcify in vitro; furthermore, healing of rickets occurs in patients in whom plasma phosphate is maintained within normal limits by means of an intravenous phosphate infusion (Fraser et al., 1957, 1958).

There are two main theories to account for the low plasma phosphate found in familial and nonfamilial hypophosphataemia. The first is that it is due to a primary defect in renal tubular reabsorption (Dent, 1952; Fanconi and Girardet, 1952) and intestinal absorption of phosphate (Condon, Nassim, and Rutter, 1970). The second is that there is a vitamin D'resistance' which results in defective intestinal absorption of calcium. The resulting calcium deficiency causes increased secretion of parathyroid hormone, which inhibits renal tubular reabsorption of phosphate and by this mechanism

Received 22 December 1970. leads to hypophosphataemia. This second theory obviously depends upon the presence of a primary defect in calcium adsorption from the gut and a resistance to the actions of vitamin $\mathrm{D}$.

In order to verify or disprove this hypothesis, intestinal calcium absorption was assessed in patients with familial hypophosphataemia and normal control subjects by means of a calcium tolerance test. The calcium tolerance curves were similar in normal subjects and in patients with familial hypophosphataemia, suggesting that intestinal calcium absorption was normal in this disorder.

Intestinal absorption of phosphate was also studied by means of a phosphate tolerance test in two patients with vitamin $\mathrm{D}$ deficient osteomalacia. The phosphate tolerance test, which has previously been shown to be flat in familial hypophosphataemic vitamin $\mathrm{D}$ resistant rickets and osteomalacia (Condon et al., 1970), was normal in vitamin D deficient osteomalacia (Condon et al., 1970). This suggests that defective intestinal absorption of phosphate in familial hypophosphataemia is not related to abnormal metabolism of vitamin $D$.

Our findings support the theory that defective renal tubular reabsorption of phosphate in familial hypophosphataemia is a primary defect and is not 
due to hyperparathyroidism which develops secondary to defective intestinal adsorption of calcium. It is suggested that rickets and osteomalacia in familial and some cases of non-familial hypophosphataemia is unrelated to abnormal metabolism of vitamin $\mathrm{D}$, but is due to a partial metabolic block in the intestinal absorption and renal tubular reabsorbtion mechanism for phosphate.

\section{Materials and Method}

The calcium tolerance tests were performed on 6 normal subjects and 3 patients with familial hypophosphataemia. 2 of these subjects had been treated with vitamin $D$ for refractory rickets, but all treatment had been stopped at least two years before the present investigation.

Phosphate tolerance tests were performed on 2 patients with vitamin D deficient osteomalacia. Phosphate tolerance tests performed on the same 3 patients with familial hypophosphataemia and normal control subjects have already been reported (Condon et al., 1970).

One of the vitamin $\mathrm{D}$ deficient patients had steatorrhoea due to pancreatic disease. Her plasma calcium was $6.5 \mathrm{mg} / 100 \mathrm{ml}$, plasma phosphate $2.6 \mathrm{mg} / 100 \mathrm{ml}$, and plasma alkaline phosphatase 24 King Armstrong units. There were Looser's zones in the right inferior pubic rami, and bone biopsy was diagnostic of osteomalacia.

The other vitamin $\mathrm{D}$ deficient subject had a dietary vitamin $\mathrm{D}$ deficiency. Plasma calcium was $8.0 \mathrm{mg} /$ $100 \mathrm{ml}$, plasma phosphate $2.4 \mathrm{mg} / 100 \mathrm{ml}$, and plasma alkaline phosphatase 18 King Armstrong units. Looser's zones were noted in the left inferior pubic ramus and a bone biopsy was diagnostic of osteomalacia.

Calcium tolerance test. All subjects were fasted overnight and received nothing to eat or drink the next morning. Immediately before the beginning of the tolerance test the patients urinated, and the urine was discarded. $32 \mathrm{~g}$ of calcium lactate/gluconate ( $\equiv 2 \mathrm{~g} \mathrm{Ca}$ ) in the form of Sandocal was dissolved in $200 \mathrm{ml}$ water and administered orally over 2 minutes. Venous blood samples collected in heparin were withdrawn 2 minutes before and $45,90,135$, and 210 minutes after ingestion of the calcium solution. Plasma calcium estimations were performed on these samples by atomic absorption spectrophotometry (Unicam S.P. 90) using the Unicam atomic absorption method $\mathrm{Ca}_{2}$ (Unicam publications). Calcium values were corrected for plasma specific gravity (Dent, 1962).

The procedure for the phosphate tolerance test has previously been described in detail (Condon et al., 1970): $6.9 \mathrm{~g}$ sodium phosphate ( $\equiv 1.5 \mathrm{~g} \mathrm{P}$ ) was dissolved in $200 \mathrm{ml}$ water and ingested by the patient who had fasted overnight. Venous blood samples collected in heparin were withdrawn 2 minutes before and 30,60, 90, 150, and 210 minutes after ingestion of phosphate solution. Plasma phosphate was estimated on these samples using the Technicon autoanalyser method N4b (Technicon autoanalyser handbook).

\section{Results}

Detailed results are given in Table I.

TABLE I

Rise in Plasma Calcium (mg/100 ml) after Ingestion of Calcium Lactate/Gluconate Solution (2 $\mathrm{g} \mathrm{Ca}$ )

\begin{tabular}{|c|c|c|c|c|c|}
\hline \multirow{2}{*}{ Case No. } & \multicolumn{5}{|c|}{ Time (min) } \\
\hline & $\mathbf{0}$ & 45 & 90 & 135 & 210 \\
\hline $\begin{array}{l}1 \\
2 \\
3\end{array}$ & $\begin{array}{c}\text { Pat } \\
0 \\
0 \\
0\end{array}$ & $\begin{array}{c}\text { with f } \\
0 \cdot 30 \\
0 \cdot 30 \\
0 \cdot 40\end{array}$ & $\begin{array}{c}\text { hypop } \\
0.60 \\
0.60 \\
0.50\end{array}$ & $\begin{array}{c}\text { ataemia } \\
0.80 \\
0.70 \\
0.65\end{array}$ & $\begin{array}{l}0.80 \\
0 \cdot 70 \\
0.60\end{array}$ \\
\hline Mean & 0 & $0 \cdot 33$ & 0.56 & $0 \cdot 72$ & $0 \cdot 70$ \\
\hline $\begin{array}{l}4 \\
5 \\
6 \\
7 \\
8 \\
9\end{array}$ & $\begin{array}{l}0 \\
0 \\
0 \\
0 \\
0 \\
0\end{array}$ & $\begin{array}{l}\text { Con } \\
0.50 \\
0.25 \\
0.50 \\
0.20 \\
0.45 \\
0.10\end{array}$ & $\begin{array}{r}\text { ubjects } \\
0 \cdot 70 \\
0 \cdot 60 \\
0.70 \\
0.50 \\
0.65 \\
0.70\end{array}$ & $\begin{array}{l}0.50 \\
0.50 \\
0.70 \\
0.50 \\
0.65 \\
0.40\end{array}$ & $\begin{array}{l}0.50 \\
0.30 \\
0.70 \\
0.30 \\
0.65 \\
0.30\end{array}$ \\
\hline Mean & & $0 \cdot 33$ & $0 \cdot 64$ & 0.54 & 0.46 \\
\hline
\end{tabular}

After an oral calcium load ( $\equiv 2 \mathrm{~g} \mathrm{Ca}$ ) the average maximum rise in plasma calcium in the normal subjects was $0.65 \mathrm{mg} / 100 \mathrm{ml}$ and that of the other patients with familial hypophosphataemia $0.72 \mathrm{mg} /$ $100 \mathrm{ml}$. This difference is not significant. Details of the phosphate tolerance tests on the 2 patients with vitamin $\mathrm{D}$ deficient osteomalacia are shown in Table II.

TABLE II

Rise in Plasma Phosphate $(\mathrm{mg} / 100 \mathrm{ml})$ after Ingestion of $6.9 \mathrm{~g}$ Sodium Phosphate Dissolved in $200 \mathrm{ml}$ Water in Two Patients with Vitamin D deficient Osteomalacia

\begin{tabular}{|c|c|c|c|c|c|}
\hline \multirow{2}{*}{ Case No. } & \multicolumn{5}{|c|}{ Time (min) } \\
\hline & 30 & 60 & 90 & 150 & 210 \\
\hline $\begin{array}{l}10 \\
11\end{array}$ & $\begin{array}{l}0.3 \\
0.2\end{array}$ & $\begin{array}{l}0.6 \\
0.4\end{array}$ & $\begin{array}{l}1 \cdot 2 \\
1 \cdot 8\end{array}$ & $\begin{array}{l}1 \cdot 2 \\
2 \cdot 1\end{array}$ & $\begin{array}{l}1 \cdot 1 \\
1 \cdot 8\end{array}$ \\
\hline Mean & 0.25 & 0.5 & $1 \cdot 5$ & $1 \cdot 65$ & $1 \cdot 45$ \\
\hline
\end{tabular}

The patients with vitamin $\mathrm{D}$ deficient osteomalacia had normal phosphate tolerance tests (normal maximum rise in plasma phosphate $1.59 \pm$ $0.46 \mathrm{mg} / 100 \mathrm{ml}$ ). Details of the phosphate tolerance tests on the patients with familial hypophosphataemia have already been reported (Condon et al., 1970) and such subjects show an abnormally flat curve with a maximum rise in plasma phosphate 
of 0.6 to $0.7 \mathrm{mg} / 100 \mathrm{ml}$ after ingestion of $6.9 \mathrm{~g}$ sodium phosphate (Fig.).

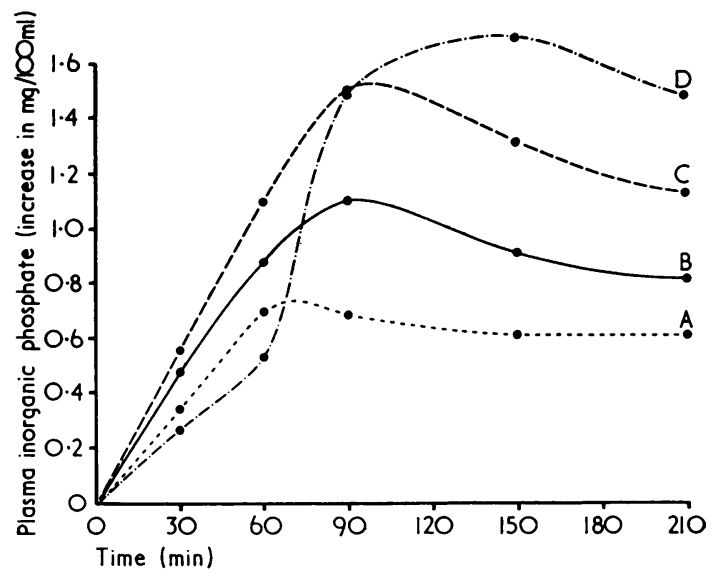

FIG.-Rises in plasma phosphate $(\mathrm{mg} / 100 \mathrm{ml}$ ) in four groups of patients after ingestion of $6.9 \mathrm{~g}$ sodium phosphate: patients with familial and non-familial hypophosphataemia $(A)$; patients with familial and non-familial hypophosphataemic rickets and osteomalacia receiving calciferol (B); normal control subjects $(C)$; and patients with vitamin $D$ deficient osteomalacia $(D)$.

\section{Discussion}

In familial hypophosphataemic rickets and osteomalacia, balance studies have shown that there is a high faecal calcium (Albright, Butler, and Bloomberg, 1937; Freeman and Dunsky, 1950; Stickler, 1963) and a high faecal phosphate (Albright et al., 1937; Robertson, Harris, and McCune, 1942; Fanconi and Girardet, 1952; Rupp, 1955). Defective intestinal absorption of phosphate has also been shown by means of an oral phosphate tolerance test (Condon et al., 1970).

Although it has generally been accepted that defective intestinal absorption of phosphate is secondary to defective intestinal absorption of calcium, a decrease in faecal calcium occurs during prolonged intravenous phosphate infusion. This finding indicates that calcium absorption can be increased indirectly and is consistent with a secondary rather than a primary suppression of intestinal calcium absorption (Wilson et al., 1965; Frame et al., 1965).

We have found that intestinal calcium absorption, as assessed by a tolerance test, is normal in fasting patients with familial hypophosphataemia though the phosphate tolerance test is abnormally flat. These findings suggest that there is a primary defect in intestinal absorption of phosphate in familial hypophosphataemia, whereas intestinal absorption of calcium is normal. In order to account for the high faecal calcium reported in balance studies, it is suggested that excess phosphate in the gut lumen interferes with calcium absorption by the formation of a relatively insoluble calcium phosphate complex, defective intestinal absorption of calcium in familial hypophosphataemia being secondary to a primary defect in absorption of phosphate from the gut.

The exact role played by vitamin $\mathrm{D}$ in the pathogenesis of hypophosphataemic bone disease is unknown. Though patients with familial hypophosphataemia are resistant to the antirachitic action of vitamin $D$, they are unfortunately not resistant to its toxic effects, and hypercalcaemia and hypercalciuria due to vitamin $\mathrm{D}$ intoxication are not infrequently observed during therapy. There is evidence that vitamin D is not metabolized as rapidly as it is normally in the majority of patients with hypophosphataemic rickets (Alvioli, McDonald, and Williams, 1966; DeLuca et al., 1967), and characteristically there is a low fractional turnover rate of the vitamin with decreased conversion to its biologically active metabolite. There have, however, been no studies of vitamin D metabolism during administration of intravenous phosphate to subjects with familial or non-familial hypophosphataemic bone disease, and it is possible that the decreased rate of vitamin $\mathrm{D}$ metabolism is due to the low plasma phosphate level invariably found in familial hypophosphataemia. Furthermore, a percentage of vitamin $\mathrm{D}$ is converted to its biologically active form, and this is also suggested by the fact that hypercalcaemia and hypercalciuria can be induced in subjects with familial hypophosphataemia by administration of large doses of vitamin $\mathrm{D}$.

It has been shown that patients with familial hypophosphataemia have defective intestinal absorption of phosphate when measured by means of an oral phosphate tolerance test (Condon et al., 1970). If familial hypophosphataemic vitamin D refractory bone disease were due to failure of action of vitamin $\mathrm{D}$ or one of its metabolites, one would have expected the phosphate tolerance curve to be flat in vitamin $\mathrm{D}$ deficient osteomalacia. This was not so, the phosphate tolerance test being normal in the 2 patients with vitamin D deficient osteomalacia yet flat in the patients with familial hypophosphataemia.

These findings suggest that the rickets and osteomalacia of familial hypophosphataemia are unrelated to the low fractional turnover rate and decreased conversion of vitamin $D$ to its biologically active 
metabolite. It is suggested that the abnormalities in the rate of vitamin D metabolism in familial hypophosphataemia are secondary to the low plasma phosphate invariably found in this disorder. There are no studies of vitamin D metabolism in patients with familial hypophosphataemia in whom plasma phosphate has been maintained within normal limits by means of a phosphate infusion, and it is possible that vitamin $\mathrm{D}$ metabolism is normal under these circumstances.

We thank Dr. P. G. Walker for his advice and help.

\section{REFERENCES}

Albright, F., Butler, A. M., and Bloomberg, E. (1937). Rickets resistant to vitamin D therapy. American fournal of Diseases of Children, 54, 529.

Alvioli, L. V., McDonald, J. E., and Williams, T. F. (1966). Abnormal metabolism of vitamin $D_{3}$ vitamin in D-resistant rickets and familial hypophosphatemia. Fournal of Clinical Investigation, 45, 982.

Condon, J. R., Nassim, J. R., and Rutter, A. (1970). Defective intestinal phosphate absorption in familial and non-familial hypophosphataemia. British Medical fournal, 3, 138.

DeLuca, H. F., Lund, J., Rosenbloom, A., and Lobeck, C. C. (1967). Metabolism of tritiated vitamin $\mathrm{D}_{3}$ in familial vitamin D-resistant rickets with hypophosphatemia. Fournal of Paediatrics, 70, 828.
Dent, C. E. (1952). Rickets and osteomalacia from renal tubule defects. Fournal of Bone and foint Surgery, 34B, 266.

Dent, C. E. (1962). Some problems in hyperparathyroidism. British Medical fournal, 2, 1419.

Fanconi, G., and Girardet, P. (1952). Familiarer persistierender Phosphatdiabetes mit D-vitamin-resistenter Rachitis. Helvetica Paediatrica Acta, 7, 14

Frame, B., Arnstein, A. R., Frost, H. M., and Smith, R. W., Jr. (1965). Resistant osteomalacia: studies with tetracycline bone labeling and metabolic balance. American fournal of Medicine, 38, 134.

Fraser, D., Geiger, D. W., Munn, J. D., Slater, P. E., Jahn, R., and Liu, E. (1958). Calcification studies in clinical vitamin D deficiency and in hypophosphatemic vitamin D-refractory rickets: the indication of calcium deposition in rachitic cartilage without the administration of vitamin D. American fournal of Diseases of Children, 96, 460.

Fraser, D.,Jaco, N. T., Yendt, E. R., Munn, J. D., and Liu, E. (1957). The induction of in vitro and in vivo calcification in bones of children suffering from vitamin D-resistant rickets without recourse to large doses of vitamin D. American fournal of Diseases of Children, 93, 84.

Freeman, S., and Dunsky, I. (1950). Resistant rickets. American Fournal of Diseases of Children, 79, 409.

Robertson, B. R., Harris, R. C., and McCune, D. J. (1942). Refractory rickets: mechanism of therapeutic action of calciferol. American Fournal of Diseases of Children, 64, 948.

Rupp, W. (1955). Untersuchungen der Phosphorsäureester mit Radiophosphor und Papierionophorese. Helvetica Paediatrica Acta, 10, 111.

Stickler, G. B. (1963). External calcium and phosphorus balances in vitamin D-resistant rickets. Fournal of Pediatrics, 63, 942.

Wilson, D. R., York, S. E., Jaworski, Z. F., and Yendt, E. R. (1965). Studies in hypophosphatemic vitiman D-refractory osteomalacia in adults. Medicine, 44, 99. 